\title{
Assessment of solar ultraviolet radiation in Tabriz city, Iran
}

\section{P. Mehnati ${ }^{1}$, H. Sabri², R. Meynaghizadeh Zargar ${ }^{1}$, Y. Rasoulzadeh ${ }^{3}$, D. Mahmoudi ${ }^{3}$, R. Malekzadeh ${ }^{1,4^{*}}$}

\author{
${ }^{1}$ Department of Medical Physics, School of Medicine, Tabriz University of Medical Sciences, Tabriz, Iran \\ ${ }^{2}$ Department of Physics, University of Tabriz, Tabriz, Iran \\ ${ }^{3}$ Occupational Health Engineering Department, Tabriz University of Medical Sciences, Tabriz, Iran \\ ${ }^{4}$ Student Research Committee, Tabriz University of Medical Sciences, Tabriz, Iran
}

Original article
Derresponding authors:
*Coza.malek78@yahoo.com
E-mail:
Revised: June 2020
Accepted: July 2020
Int. J. Radiat. Res., April 2021;
19(2): 437-441
DoI: 10.29252/ijrr.19.2.437

\begin{abstract}
Background: The solar radiation consists of a vast spectrum of wavelengths such as visible light and ultraviolet radiation (UVR). The amount of UVR that reaches the Earth's surface is very important due to its role in vitamin D synthesis and causing skin cancers. The hourly and daily mean values of solar UV type A, B, and visible light radiation were measured for the first time during the year. Materials and Methods: The hourly and daily mean values of UVR and visible light intensity of solar radiation at Tabriz were measured and analyzed between the 2017 and 2018 years. The intensity of solar UVA and UVB radiation was measured by Hand-held Lux-UV meter device from sunrise to sunset for one hour. Results: The results showed that the highest values of UVA and UVB radiation, reaching the Earth were between 12 and 13 o'clock. The maximum and minimum values of UVR were recorded during the months of May and January, respectively. The maximum amounts of UVA and UVB during the whole year were 52.48 and $2.82 \mathrm{~W} / \mathrm{m}^{2}$, respectively. Also, the lowest intensity of UVA and UVB radiation during the whole year was 22.19 and $0.79 \mathrm{~W} / \mathrm{m}^{2}$, respectively. Conclusion: Comparison of maximum and minimum UV amounts of type A and B in May was about 2.36 and 3.56 times more than in January. The measurements showed that the intensity of UVA was significantly higher than UVB amounts.
\end{abstract}

Keywords: Solar ultraviolet radiation, UVA, UVB, visible light, Iran.

\section{INTRODUCTION}

Ultraviolet (UV) is a part of the electromagnetic spectrum, with a wavelength range between $100-400 \mathrm{~nm}$. Actually, it is dangerous for human health and biochemistry of cells due to the high energy of photons in this wavelength range (1). The World Health Organization (WHO) recommends studying and monitoring the Ultraviolet radiation (UVR) because of its biological effects in living organisms (2). Based on the benefits and the risks of UVR, it can be classified into three sections including UVA (400-315 nm), UVB (315-280 $\mathrm{nm})$, and UVC (280-100 $\mathrm{nm})^{(3)}$.
The UVC band is mostly absorbed by the ozone $\left(\mathrm{O}_{3}\right)$ layer and atmosphere. UVB part of the solar radiation is most effective in causing diseases such as sunburn, skin cancer, and eye diseases. However, vitamin D is also essential for synthesis in the skin of mammals. UVA is hardly affected by ozone and most of it reaches Earth's surface. It can penetrate into the eye and skin much deeper, due to its longer wavelength and cause some injuries (4).

Recently, concerns have been raised about the intensity of ground-levels of UVB radiation due to the stratospheric ozone depletion and a dramatic increase in the number of skin cancers in the population around the world (5). The 
increasing evidence of global stratospheric ozone reduction highlights the importance of monitoring ground-level UVR (6). Studies have shown that there is a relationship between UVR and the amount of ozone and found that a 1\% ozone reduction leads to a $1.25 \%$ growth in UVR (7). Cloudiness often affects the UVR on the Earth's surface and may depend on the amount and type of the cloud, reducing or increasing the UVR. Moreover, time of the day, season, latitude, altitude (radiation rises 10\%-12\% every 1000 $\mathrm{m}$ ), fog, and pollutants (block and decrease exposure) are among factors that determine the amount of the UVR reached the Earth surface.

Given the potential applications of solar energy, many studies have been conducted to measure the intensity of solar radiation in different regions of Iran as well as in neighboring countries (8). Iran receive a sufficient amount of sunlight that enables the cutaneous synthesis of vitamin D in most months of the year $\left.{ }^{9}\right)$. Approximately $90 \%$ of the body's need for vitamin $\mathrm{D}$ has to be produced in the skin through the action of solar UVB radiation (10). However, Heshmat et al., showed the prevalence of vitamin $\mathrm{D}$ deficiency in a multi-center study among the Iranian population with a large sample size (11). They found that both sexes including residents of Tabriz city were greatly suffered from vitamin D deficiency in all urban regions. Vitamin D status also plays an important role in preventing various cancers (12).

This study aimed to evaluate the intensity of UVA and UVB radiation as well as visible light intensity throughout the 2017-2018 year because annual UVR data were not reported in Tabriz. Also, due to the high prevalence of UV-related diseases, the information obtained through this study can be useful for community health officials in terms of planning for the prevention of skin diseases, elimination of vitamin $\mathrm{D}$ deficiency and personal protection against radiation.

\section{MATERIALS AND METHODS}

Tabriz $\left(38^{\circ} 4^{\circledR} \mathrm{E}, 46^{\circ} 18^{\mathrm{E}} \mathrm{E}\right.$, height: 1,350 - 1,600 m) is the center of East Azerbaijan Province of Iran with four regular seasons.

\section{Instrumentation}

Multiband hand-held UV-IR- lux meter (Lux-UV-IR meter 666 230, LEYBOLD, Hürth, Germany) was used to measure solar UVA, UVB and visible light intensity with suitable sensors and evaluated with the hand-held UV-IR lux meter. The calibration with a sun-like spectrum was done by the manufacturer and the radiation is evaluated according to the response curves. The calibration factor is imprinted on the sensor tube. Table 1 shows a summary of the device specifications.

Table 1. Characteristics of the solar radiation measuring by separate sensors of UVA, UVB and visible light.

\begin{tabular}{|c|c|c|c|c|}
\hline Sensors & $\begin{array}{c}\text { Measuring } \\
\text { Range }\end{array}$ & $\begin{array}{c}\text { Curve } \\
\text { Peak }\end{array}$ & $\begin{array}{c}\text { Calibration } \\
\text { Factor }\end{array}$ & Units \\
\hline $\begin{array}{c}\text { UVA sensor } \\
\text { (666 244) }\end{array}$ & $320-400$ & 346 & 0.96 & $\mathrm{~W} / \mathrm{m}^{2}$ \\
\hline $\begin{array}{c}\text { UVB sensor } \\
\text { (666 245) }\end{array}$ & $280-330$ & 304 & 2.00 & $\mathrm{~W} / \mathrm{m}^{2}$ \\
\hline $\begin{array}{c}\text { Lux sensor } \\
\text { (666 243) }\end{array}$ & $\begin{array}{c}\text { Visible } \\
\text { Light }\end{array}$ & - & 0.74 & $\begin{array}{c}\text { Lux } \\
\left.\text { (lumen } / \mathrm{m}^{2}\right)\end{array}$ \\
\hline
\end{tabular}

\section{Data collection}

This is a cross-sectional study from July 2017 to July 2018 for one year. Research methods including the record of UVR using a measurement station located at the campus of Tabriz University of Medical Sciences without high buildings and with a distance of more than $70 \mathrm{~m}$. Measurements were done outdoors under sunlight, and the sensors were placed in a horizontal position one meter above the ground to prevent disruption of reflected UVR. Measurements were done from sunrise to sunset for one hour. The data were continuously collected for three days one week and in different weather conditions. This research was conducted in a constant position with a surface covered by grass. For each period, measurements were repeated five times to minimize the possible errors and to calculate the mean values. The daily and monthly statistics were obtained from the hourly data set for the whole year.

Int. J. Radiat. Res., Vol. 19 No. 2, April 2021 


\section{Statistical analysis}

SPSS software version 16.0 and ANOVA test were used for the statistical analysis, and the p-value $<0.05$ was considered statistically significant. All experiments were performed as a minimum of five independent replicates, presented as mean \pm standard deviation (SD).

\section{RESULTS}

The daily changes from the hourly values of UVR types $A$ and $B$, as well as the intensity of light are shown in figure $1(\mathrm{~A}-\mathrm{C})$. The average monthly changes were quite regular, with the highest values in May/Jun and the least in January/December.

The mean annual cumulative frequency distribution of hourly solar irradiance values, for UVA, UVB and visible light intensity are also shown in table 2 . The results demonstrated that the highest solar radiation that reaches the Earth was between 10 and 15 o'clock. The cumulative doses reaches in the time between 10 and 15 o'clock were about 50.07\% (UVA), $70.77 \%$ (UVB) of daily accumulated UVR through a year. As it is shown in table 2, the intensity of visible light that reaches the Earth from 9 am to $5 \mathrm{pm}$ is approximately the same for periods of time (almost $12 \%$ of total radiation).

Monthly changes in solar ultraviolet and visible light intensity in Tabriz for one year were shown in figure 2 (A-C). The solar radiation values in spring and summer are much higher than autumn and winter, and spring (May) values were also slightly higher than summer.
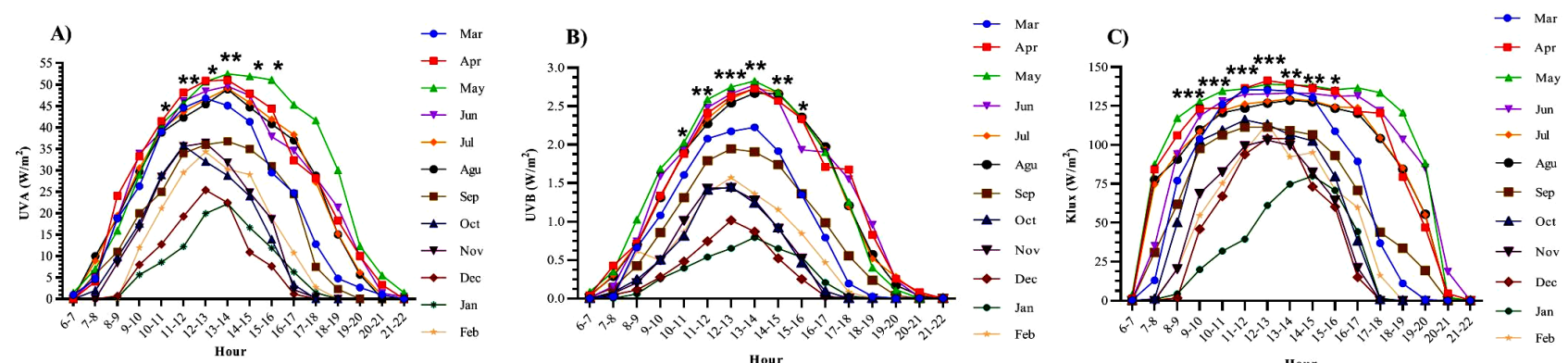

Figure 1. The monthly average per hours of day for solar ultraviolet and visible light intensity were shown as a A: UVA (ultraviolet type A), B: UVB (ultraviolet type B) and C: visible light in Tabriz, Iran. Significancy of data was shown with * and ** (*:

Pvalue $<0.05, * *$ : P value $<0.01$ ). The stars indicate a significant difference in the amount of ultraviolet light and visible light between different hours of the day. It is observed that for all months, the sunlight intensity increases significantly between $10-16$ pm.
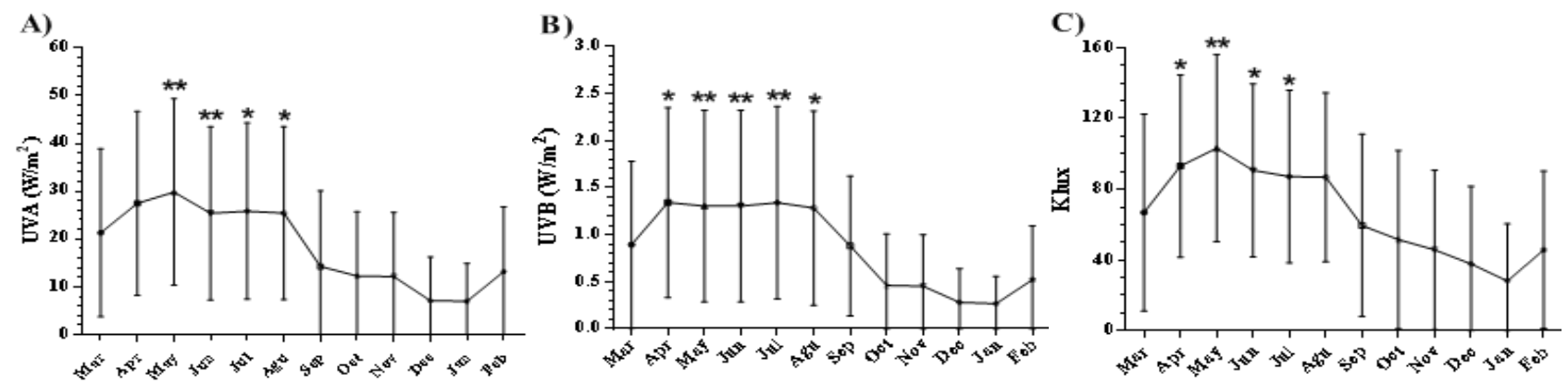

Figure 2. Monthly variations of solar ultraviolet and visible light intensity over a year presented as A: UVA (ultraviolet type A), B: UVB (ultraviolet type B) and C: visible light in Tabriz, Iran. Significancy of data was shown with * and ** (*: Pvalue <0.05, **: P value $<0.01)$. The stars indicate a significant difference in the amount of ultraviolet light and visible light between different months of year. 
Table 2. Distribution over one year of ultraviolet type $A$ (UVA), ultraviolet type B (UVB) and visible light in Tabriz, Iran.

\begin{tabular}{|c|c|c|c|}
\hline Hours & UVA (\%) & UVB (\%) & Visible light (\%) \\
\hline $6-7$ & 0.28 & 0 & 0.18 \\
\hline $7-8$ & 1.26 & 0.17 & 1.0 \\
\hline $8-9$ & 5.15 & 4.70 & 6.98 \\
\hline $9-10$ & 7.86 & 7.66 & 9.42 \\
\hline $10-11$ & 11.29 & 11.36 & 11.43 \\
\hline $11-12$ & 12.51 & 14.71 & 12.27 \\
\hline $12-13$ & 13.19 & 15.39 & 12.28 \\
\hline $13-14$ & 13.10 & 15.57 & 12.21 \\
\hline $14-15$ & 12.21 & 13.56 & 11.82 \\
\hline $15-16$ & 8.91 & 9.56 & 9.87 \\
\hline $16-17$ & 7.34 & 5.59 & 8.11 \\
\hline $17-18$ & 4.27 & 1.37 & 3.35 \\
\hline $18-19$ & 1.59 & 0.18 & 0.78 \\
\hline $19-20$ & 0.81 & 0 & 0.22 \\
\hline $20-21$ & 0.26 & 0 & 0 \\
\hline
\end{tabular}

\section{DISCUSSION}

In this study, the solar UVA and UVB radiation intensity of Tabriz city was measured for a whole year. The intensity of visible light as well as UVR for all seasons increased rapidly in the early hours of the day and decreased at the end of the day.

Also, due to the distance between the Earth and the sun during summer and winter, solar radiation is higher in the summer. These behaviors might be caused by rain and higher air mass (air molecules, water vapor, clouds, and dust) in winter. The higher air mass in winter can reduce the radiation by diffusing (absorbing, scattering and reflecting) during the long path. The lowest and highest average intensity levels of solar UVA in Kermanshah were in December $\left(14.21 \mathrm{~W} / \mathrm{m}^{2}\right)$ and August $\left(32.87 \mathrm{~W} / \mathrm{m}^{2}\right)$, respectively (13). Maximum UVA values were always obtained between 12:30 and 13:30 o'clock. However, for most months of the year, the highest amounts of UVB radiation were obtained between 13 and 14 o'clock (figure 1). Our results are in agreement with the results presented by similar studies established in the other cities of Iran (13-15).

UVA values, as expected, were above average UVB values, due to the stratospheric ozone absorption effect and other mentioned considerable factors. According to figure 1, the lowest and highest amounts of UVA radiation during the year were in January $\left(22.19 \mathrm{~W} / \mathrm{m}^{2}\right)$ and May $\left(52.48 \mathrm{~W} / \mathrm{m}^{2}\right)$, respectively. These results for UVB were in January $\left(0.79 \mathrm{~W} / \mathrm{m}^{2}\right)$ and May $\left(2.82 \mathrm{~W} / \mathrm{m}^{2}\right)$. The maximum amounts of UV types A and B in May were about 2.36 and 3.56 times more in January, respectively. The data analysis showed that the average amount of UVA radiation was more than 200 times higher than the UVB values for the mentioned months.

By estimating seasonal cumulative UVA doses, we measured $35 \%$ of the cumulative annual dose in spring, $33 \%$ in summer, $18 \%$ in autumn and $13 \%$ in winter. In the case of UVB, $34 \%$ was received in spring, $39 \%$ in summer, $15 \%$ in autumn and $11 \%$ in winter. Similar behavior was observed regarding light intensity throughout the year: $33 \%$ of cumulative annual doses in the spring, $32 \%$ in the summer, $19 \%$ in the autumn and $14 \%$ in the winter. Low values of solar irradiance in the fall and winter seasons are probably due to unstable local weather conditions and low sunshine hours. Also, the value of light intensity can be used to define the sky condition. Many studies have examined the relationship between brightness, cloudiness and precipitation (16). UV distribution values are also important for monitoring the synthesis of vitamin D in the human body. In addition, knowing that how much solar radiation reaches during hours of a day has other environmental benefits such as planning and using solar energy systems (17).

Tavakoli et al., reported the Earth's UV values from January to the end of December 2003 in Esfahan City. They found that the measuered UVA level was around 11 to 21 times more than UVB radiation. The highest mounthly UV radiation appeared in July while the lowest value was in January(14). In similar study, Behrooz et al., measured the solar UVA amounts over a year in the southwest of Iran, Ahvaz city. The results showed that maximum and minimum levels of UVR were in May $\left(43 \mathrm{~W} / \mathrm{m}^{2}\right)$ and January $\left(20 \mathrm{~W} / \mathrm{m}^{2}\right)$, respectively (15). In addition, a cross-sectional study was conducted in Yazd city (geographical center of Iran) to evaluate the

Int. J. Radiat. Res., Vol. 19 No. 2, April 2021 
amount of UVA rays. The results showed that maximum and minimum levels of UV were in July and December, respectively (16). Nearly the same conclusion has been obtained by Rostampour et al. for Hamedan. They assessed solar UVA radiation in Hamedan city. They found that UVA radiation was maximum in September $\left(27 \mathrm{~W} / \mathrm{m}^{2}\right)$, while the least level was in December $\left(19 \mathrm{~W} / \mathrm{m}^{2}\right)$ (19). They showed that more than $60 \%$ of UV radiation reached between $11 \mathrm{am}$ to $3 \mathrm{pm}$ when UV radiatin pass through the atomosphere in dierect component as there are few molecules to scatter radiation.

\section{CONCLUSION}

In the present study, the hourly intensity of solar UV (A and B) radiation and visible light were presented in Tabriz. Comparison of maximum and minimum UV levels of Type A and B in May was around 2.36 and 3.56 times more than recorded in January. The measurements showed that the UVA intensity was significantly higher than UVB values.

\section{ACKNOWLEDGMENTS}

This study was supported by student research committee of Tabriz University of Medical Sciences, Tabriz, Iran.

\section{Conflicts of interest: Declared none.}

\section{REFERENCES}

1. Del ZG and Mason HE (2018) Solar UV and X-ray spectral diagnostics. Living rev sol phys, 15(1): 5.

2. Mullenders L (2018) Solar UV damage to cellular DNA: from mechanisms to biological effects. Photochem Photobiol Sci, 17(12): 1842-52.

3. Gies $P$, van Deventer E, Green AC, Sinclair C, Tinker R (2018) Review of the global solar UV index 2015 workshop report. Health Phys, 114(1): 84.
4. Madronich S, Björn LO, McKenzie RL (2018) Solar UV radiation and microbial life in the atmosphere. Photochem Photobiol Sci, 17(12): 1918-31.

5. Bais AF, Bernhard G, McKenzie RL, Aucamp P, Young PJ, Ilyas $M$, et al. (2019) Ozone-climate interactions and effects on solar ultraviolet radiation. Photochem Photobiol Sci, 18(3): 602-40.

6. Jardine PE, Fraser WT, Gosling WD, Roberts CN, Eastwood WJ, Lomax BH (2020) Proxy reconstruction of ultraviolet-B irradiance at the Earth's surface, and its relationship with solar activity and ozone thickness. The Holocene, 30(1): 155-61.

7. Egorova T, Rozanov E, Arsenovic P, Sukhodolov T (2020) Ozone Layer Evolution in the Early 20th Century. Atmosphere, 11(2): 169.

8. Al Mahdi N, Al Baharna N, Zaki F (1992) Assessment of solar radiation models for the Gulf Arabian countries. Renew Energ, 2(1): 65-71.

9. Hamzeh $Y$, Ashori A, Mirzaei B, Abdulkhani A, Molaei M (2011) Current and potential capabilities of biomass for green energy in Iran. Renew Sust Energ Rev, 15(9): 4934-8.

10. Holick MF (2008) Sunlight, UV-radiation, vitamin D and skin cancer: how much sunlight do we need? Sunlight, Vitamin D and Skin Cancer. Springer.

11. Heshmat R, Mohammad K, Majdzadeh S, Forouzanfar M, Bahrami A, Ranjbar Omrani G (2008) Vitamin D deficiency in Iran: A multi-center study among different urban areas. Iran J Public Health, 37(1): 72-8.

12. Farhood B, Raei B, Malekzadeh R, Ameri H, Shirvani M, Alizadeh A, Najafi M, et al. (2019) A review of incidence and mortality of colorectal, lung, liver, thyroid, and bladder cancers in Iran and compared to other countries. Contem Oncol, 23(1): 7-15.

13. Rezaei M, Khoshgard K, Mafakheri H, Kanaani M (2019) The measurement of solar ultraviolet radiation in Kermanshah city over a one-year period from 2015 to 2016. Int J Radiat Res, 15(4): 419-23.

14. Tavakoli M and Shahi Z (2007) Solar ultraviolet radiation on the ground level of Isfahan. Int J Radiat Res, 5(2): 1014.

15. Behrooz M, Seif F, Fattahiasl J, Behrooz L (2010) Variation of cosmic ultraviolet radiation measurements in Ahvaz at different months of year. Sci Med, 9(1): 45-51.

16. Bouzarjomehri F and Tsapaki V (2012) Measurement of solar ultraviolet radiation in Yazd, Iran. Int J Radiat Res, 10 (3): 187-91.

17. Kassianov E, Barnard J, Berg LK, Long CN, Flynn C (2011) Shortwave spectral radiative forcing of cumulus clouds from surface observations. Geophys Res Let, 38(7).

18. Akbarian Ronizi S, Roshan GR, Negahban S (2016) Assessment of tourism climate opportunities and threats for villages located in the northern coasts of Iran. Int J Env Res, 10(4): 601-12.

19. Rostampour N, Almasi T, Rostampour M, Bayat $H$, Karimi S (2013) Assessment of Solar Ultraviolet A Radiation in Hamadan City. Sci J Hamadan Univ Med Sci, 19(4): 69-74. 
